\title{
Immunoglobulin Measurement
}

National Cancer Institute

\section{Source}

National Cancer Institute. Immunoglobulin Measurement. NCI Thesaurus. Code C81869.

The determination of the amount of immunoglobulin present in a sample. 